\title{
Estudo bibliométrico da produção científica sobre a associação de pais e amigos dos excepcionais
}

\author{
João Henrique da Silva* \\ Maria Cristina Piumbato Innocentini Hayashi**
}

\section{Resumo}

A presente pesquisa teve por objetivo analisar as produçōes científicas oriundas de teses e dissertações sobre a temática Associação de Pais e Amigos dos Excepcionais (APAE). Trata-se de um estudo quali-quantitativo, de abordagem metodológica bibliométrica e de análise de conteúdo. Os procedimentos metodológicos foram desenvolvidos em três etapas, que incluem a fase de preparação teórica e metodológica, de coleta e registro de dados e de sistematizaçáo e análise dos resultados. Os resultados apontaram que a maioria da produção acadêmica foi realizada no mestrado, entre os anos de 2008 a 2011, e por pessoas do sexo feminino. Entre os 75 trabalhos foram identificadas 29 instituições que prestam serviços de ensino concentradas nas regiôes sul e sudeste do país. Constatou-se, também, que os estudos estão direcionados para o campo de conhecimento da Saúde e Educação. A produção acadêmica analisada apresenta diferentes temáticas relacionadas à educação, bem como objetivos, tipos de estudo e resultados obtidos. Portanto, a pesquisa contribui para discutir sobre o papel das unidades apaeanas na oferta de serviço de apoio complementar ou substitutivo à educação, em vista da qualidade de ensino e efetivação dos direitos.

Palavras-chave: Educação Especial; Associação de Pais e Amigos dos Excepcionais; Análise bibliométrica.

\footnotetext{
* Doutorando em Educação Especial pela Universidade Federal de São Carlos, São Carlos, São Paulo, Brasil.
}

** Professora doutora na Universidade Federal de São Carlos, São Carlos, São Paulo, Brasil. 


\title{
Scientific production bibliometric study about 'people with deficiencies parents' association
}

\begin{abstract}
This research had as aim to analyze scientific productions from thesis and dissertations studies about 'People with Deficiencies Parents' Association (APAE). It is a quali-quantitative study of bibliometric methodological approach and content analysis. The methodological procedures were developed in three stages that include the phase of methodological and theory preparation, of collect and data registration, and of systematization and analysis of results. The results pointed out that majority of academic production were accomplished in master's degree from 2008 to 2011 and by female researchers. It was localized 29 institutions of teaching among 75 studies, which concentrated in southwest and south area of Brazil. It was evidenced as well as that studies were directed forward knowledge field about Healthy and Education. Academic production analyzed shows different themes related to education, as well as objectives, types of studies and results that they came. Therefore, this research contribute to discuss about role of units of People with Deficiencies Parents' Association in the offering of complementary support services or substitutive to education, searching quality and effectuation of rights.
\end{abstract}

Keywords: Special Education. 'People with Deficiencies Parents' Association.

Bibliometric analysis.

\section{Introdução}

A Associação de Pais e Amigos dos Excepcionais (APAE) é uma instituição filantrópica criada em 11 de dezembro de 1954, no Rio de Janeiro, por iniciativa de familiares e amigos de pessoas com deficiência. A APAE tem por objetivo principal "promover a atenção integral à pessoa com deficiência, prioritariamente aquela com deficiência intelectual e múltipla" (FENAPAES, 2014). Ao longo desses anos, ela se expandiu por todo o país, dando origem, em 1962, à Federação Nacional das APAES (FENAPAES). Essa rede associativa completou 60 anos de atividades no final de 2014. Essa organização social congrega atualmente 2.127 APAES filiadas e outras entidades congêneres, nos 26 estados brasileiros (PROCURADORIA JURÍDICAFENAPAES, 2013).

De acordo com Jannuzzi e Caiado (2013), a Rede APAE trabalha com a educação do público atendido na forma de rede paralela à educação regular. Nos dias atuais, a APAE trabalha tanto na substituição do ensino regular - depende das diretrizes da política municipal e estadual, quanto na forma de atendimento educacional especializado. A FENAPAES posiciona-se na defesa da APAE como escola especial, objetivando seu reconhecimento como instituição escolar. A política educacional garante a modalidade escolar às crianças e adolescentes com deficiência, de forma preferencial na rede regular de ensino (BRASIL, 2008, 2014), mas também abre precedentes para que as entidades sociais, como as APAES, ofertem serviços assistenciais na área da educação. 
Esse cenário instiga a compreender como se configuram os estudos oriundos da produção científica acadêmica da pós-graduação brasileira que abordam a temática das APAES. Essa proposta recorreu à abordagem bibliométrica para compreender a configuração das pesquisas em nível de dissertações e teses sobre a APAE, por meio de indicadores bibliométricos. Nos campos da Educação e da Educação Especial, grupos de pesquisa acadêmicos liderados por Hayashi e colaboradores estão desenvolvendo investigaçóes na abordagem bibliométrica para analisar diferentes objetos de estudo, além de traçar a interface desses campos de conhecimento com outras áreas, como a Fonoaudiologia, a Educação Física, o Direito, etc. Nos últimos dez anos, (2004-2014), tais pesquisas resultaram nos seguintes trabalhos: Silva (2004), Sacardo (2006), Garrutti (2007), Silva (2008), Pizzani (2008, 2012), Bello (2009, 2013), Coppede (2012), Nunes (2012) e Bravo (2013). Essas pesquisas contribuem para demonstrar a pertinência das análises da produção científica na forma de "estados da arte" das áreas de conhecimento específicas, bem como a avaliação de comportamento de publicação de pesquisadores.

Dessa forma, a presente pesquisa tem por objetivo analisar a produção científica acadêmica oriunda de teses e dissertaçôes produzidas no Brasil sobre a temática das APAES, disponível na Biblioteca Digital de Teses e Dissertaçóes do IBICT (BDTD)1, além de identificar e caracterizar essas teses e dissertaçôes de acordo com os seguintes parâmetros bibliométricos: autoria, orientação, perfil do pesquisador e do orientador, nível de estudos, configuração institucional, temporal e geográfica dos trabalhos e ainda examinar as temáticas estudadas sobre a APAE, os objetivos dessas pesquisas, os tipos de estudo desenvolvidos e os resultados obtidos.

Inicialmente, o artigo apresenta o percurso metodológico da pesquisa e, posteriormente, os resultados obtidos, com os indicadores bibliométricos e as análises dos trabalhos que estudaram a instituição APAE.

\section{Método}

Do ponto de vista metodológico, a pesquisa foi conduzida mediante a adoção das abordagens bibliométrica e da análise de conteúdo. A Bibliometria pauta-se pelo princípio de analisar a atividade científica ou técnica pelos estudos quantitativos das publicaçôes, ou seja, por meio dessa abordagem "os dados quantitativos são calculados a partir de contagens estatísticas de publicaçóes ou de elementos que reúnem uma série de técnicas estatísticas, buscando quantificar os processos de comunicação escrita" (SILVA; HAYASHI; HAYASHI, 2011, p. 113). Sacardo (2012, p. 18) complementa esse entendimento ao considerar que os estudos bibliométricos são úteis para mapear um campo científico, avaliar a pesquisa acadêmica, "[...] bem como para orientar rumos e estratégias de financiamento de pesquisas e apontar o alcance analítico para o estudo de um campo científico".

Contudo, embora as análises bibliométricas sejam frequentemente associadas a sua característica quantitativa, em virtude dos recursos matemáticos que dão suporte a essa metodologia, é preciso ultrapassar essa visão, pois, como argumentam Hayashi, Hayashi e Martinez (2008, p. 139), "as estatísticas não constituem um fim 
em si mesmas, mas são mobilizadas para analisar a dimensão coletiva da atividade de pesquisa e o processo dinâmico da construção de conhecimentos". Esses autores ainda assinalam que, apesar da Bibliometria se basear em métodos quantitativos, essa metodologia possui métodos qualitativos de análise (HAYASHI; HAYASHI; MARTINEZ, 2008, p. 139).

Além disso, sendo as análises bibliométricas um estudo de avaliação da produção científica, é necessário combiná-las com outras metodologias, pois como ressalta Minayo (2006, p. 395), "a triangulação de métodos é particularmente recomendada para os estudos de avaliação", ou seja, adota como estratégia de investigação múltiplos métodos de obtenção de informação.

Nessa direção, a utilização da análise de conteúdo tem se revelado um método eficaz para complementar os estudos bibliométricos, pois permite extrair o sentido dos textos por meio de unidades e categorias de análise.

Desse modo, a presente pesquisa vincula-se a essas perspectivas metodológicas para atingir seus objetivos, sendo possível ser caracterizada como de natureza exploratória, descritiva e interpretativa, e de caráter quali-quantitativo.

O trabalho definiu as seguintes expressóes de busca para coleta de dados, "Associação de Pais e Amigos dos Excepcionais" e "APAE" na BDTD/IBICT. Em segui$\mathrm{da}$, os dados foram coletados e registrados no protocolo de registro de dados bibliométricos (HAYASHI, 2014), utilizando o software MS Excel. A amostra dos dados constituiu-se dos trabalhos que abordassem a atuação da APAE e/ou que a elegesse como lócus de pesquisa. Por último, realizamos a organização, o tratamento bibliométrico e a análise dos dados coletados.

A leitura dos títulos dos trabalhos, dos resumos e das palavras-chave deram condiçóes de verificar a presença ou ausência do enfoque sobre a APAE. Assim, após a exclusão dos registros duplicados e daqueles que não se enquadravam no escopo da pesquisa, o corpus final pesquisado resultou em 75 trabalhos.

\section{Panorama bibliométrico da produção científica}

Verificamos que existem 63 pesquisas (84\%) realizadas em nível de mestrado, 7 no doutorado e 5 no mestrado profissionalizante, o que expóe um quadro significativo de trabalhos, em nível de mestrado, que pesquisou sobre APAE. Como revela Pereira, Júnior e Hayashi (2013), o sistema de pós-graduação brasileiro oferece muito mais cursos no mestrado, o tempo de duração desse estudo é mais curto e oferece mais vagas, ao passo que o doutorado possui um período mais longo e a oferta de vagas é menor. 
Figura 1 - Configuração temporal por nível de pesquisa

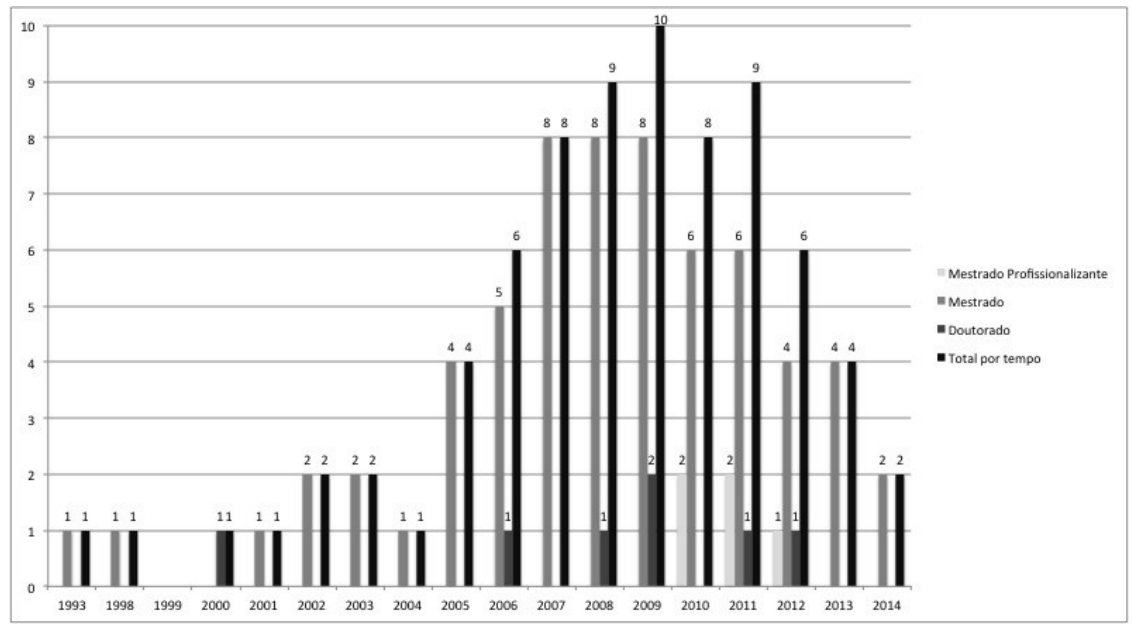

Fonte: BDTD/IBICT, 2014. Elaboração dos autores.

Os resultados na Figura 1 apresentam que as pesquisas com a expressão APAE estáo distribuídas no deccorer de 21 anos, entre 1993 a 2014. Detectamos ausência entre os anos 1994 e 1997 e em 1999. Os estudos de mestrado tiveram um crescimento expressivo no triênio 2007 a 2009 com 8 trabalhos, seguido de 6 trabalhos em 2010 e 2011. Aqueles de mestrado profissionalizante, foram realizados no triênio 2010 a 2012. Já as pesquisas de doutorado se encontraram dispersas entre 2000 a 2012, somente o ano de 2009 contou com 2 trabalhos, o que revela uma produçáo científica incipiente em nível de tese. Em geral, observamos que 2009 teve um maior número de pesquisas, seguido por 2008 e 2011.

Essa distribuição temporal sugere que as poucas pesquisas sobre a APAE entre 1994 a 1997 deve-se a oferta do número de cursos de mestrado e doutorado no país, bem como o fato de a APAE prestar um serviço de filantropia. Este corresponde a um trabalho social que instiga o sentimento de compaixáo pelas pessoas que prestam serviços na área da educação, saúde e assistência social. É interessante notar que a produção sobre a APAE cresce a partir do ano de 2005, quando o governo Lula deu início à implementação da política de "Educação Inclusiva" que implicou em novas readequaçôes das instituiçôes especializadas. Essas mudanças acentuaram-se a partir da Política Nacional de Educação Especial (2008) que, por sua vez, coincide com o grande quantitativo de pesquisas no período de 2007 a 2011.

Identificamos que a produção acadêmica abrange 75 autores de teses e dissertaçôes, o equivalente a um autor por pesquisa. A maioria, 62 corresponde ao sexo feminino, ao passo que 13 autores eram do sexo masculino. Esses resultados sustentam os argumentos de que em determinadas áreas de conhecimento, como ocorre na Educação, acontece o processo de feminização da ciência, conforme corroboram estudos sobre a participação feminina na ciência (RIGOLIN; HAYASHI; HAYASHI, 2013). 
Verificamos que 64 trabalhos foram orientados apenas por um orientador. Houve 5 pesquisadores que orientaram mais de um trabalho, a saber: Décio Brunoni (Mackenzie) com 3 trabalhos e Carlos Alberto Bezerra Tomaz (UnB), Edison Duarte (Unicamp), Gislaine Denise Czlusniak (UEPG), Neide Maria de Almeida Pinto (UFV) com 2 trabalhos cada. Assim, indica-nos que não existe concentraçáo de orientadores nas pesquisas sobre a APAE. No que concerne ao gênero de 69 orientadores, 50 são do sexo feminino ( $72 \%$ ) e 19 do sexo masculino (28\%), o que reafirma a discussão de Rigolin, Hayashi e Hayashi (2013).

Esses orientadores e autores fazem parte de 29 instituiçôes que, conforme a Tabela 1, a maioria das pesquisas concentra-se nos programas de pós-graduação da USP (16\%), em seguida na Unicamp (11\%) e UnB (8\%). Outras instituiçôes aparecem com 2 a 4 estudos, e outras 15 instituições possuem apenas um trabalho. Esses dados revelam um significativo número de instituiçôes de ensino superior que realizaram trabalhos sobre a APAE, bem como se encontram dispersos no país.

Tabela 1 - Configuração dos trabalhos por instituições

\begin{tabular}{|c|c|}
\hline Instituiçóes & Total de trabalhos \\
\hline Univ. de São Paulo (USP) & 12 \\
\hline Univ. Est. de Campinas (Unicamp) & 8 \\
\hline Univ. de Brasília (UnB) & 6 \\
\hline $\begin{array}{l}\text { Univ. Fed. de Santa Maria (UFSM), Univ. Fed.de Viçosa (UFV), Univ. Fed. do Rio Grande } \\
\text { do Sul (UFRGS), Univ. Presbiteriana Mackenzie (UPM) ( } \mathrm{n}=4 \text { ) }\end{array}$ & 16 \\
\hline $\begin{array}{l}\text { Pont. Univ. Católica de Sáo Paulo (PUC-SP), Univ. Fed. de Minas Gerais (UFMG), Univ. } \\
\text { Fed. do Maranhāo (UFMA), Univ. Regional de Blumenau (FURB) ( } \mathrm{n}=3)\end{array}$ & 12 \\
\hline $\begin{array}{l}\text { Univ. Est. de Ponta Grossa (UEPG), Univ. Fed. de Goiás (UFG), Pont. Univ. Católica de } \\
\text { Goiás (PUC-GO) }(\mathrm{n}=2)\end{array}$ & 6 \\
\hline $\begin{array}{l}\text { Escola Superior de Teologia (EST); Faculdade de Medicina de São José do Rio Preto } \\
\text { (FAMERP); Pont. Univ. Católica do Rio Grande do Sul (PUC-RS); Univ. Católica de } \\
\text { Brasília (UCB); Univ. Católica Dom Bosco (UCDB); Univ. do Est. do Rio de Janeiro } \\
\text { (UERJ); Univ. do Vale do Itajaí (Univali); Univ. Est. do Oeste do Paraná (UNIOESTE); } \\
\text { Univ. Fed. de Juiz de Fora (UFJF); Univ. Fed. de São Carlos (UFSCar); Univ. Fed. de Sáo } \\
\text { Paulo (UNIFESP); Univ. Fed. de Uberlândia (UFU); Univ. Fed. do Ceará (UFC); Univ. Fed. } \\
\text { do Pará (UFPA);Univ. Tuiuti do Paraná (UTPR) (n=1) }\end{array}$ & 15 \\
\hline Total & 75 \\
\hline
\end{tabular}

Fonte: BDTD/IBICT, 2014. Elaboração dos autores.

Se agregarmos a configuração de instituiçốes por regiôes do Brasil, verificamos que as 29 instituiçóes estão distribuídas em todas as regiôes do país, tais como: o Nordeste (2); o Centro-Oeste (5); o Norte (1); o Sul (9) e o Sudeste (12), e a maioria delas são públicas $(\mathrm{n}=19)$. Se analisarmos por quantidade de trabalhos, o Sudeste também possui o maior número de trabalhos (53\%), seguido do Sul (24\%), Centro-Oeste (16\%), Nordeste (5\%) e Norte (2\%). Como indicam Pereira, Júnior e Hayashi (2013), as regiôes Sudeste e Sul possuem uma maior concentração de programas de pós-graduação no país. Também é preciso considerar que o Sudeste possui o maior número de unidades apaeanas, qual seja 831 (equivale a aproximadamente $40 \%$ de 2.127 unidades), seguida da região Sul, com 745 instituições (PROCURADORIA JURÍDICA-FENAPES, 2013). 
Aliás, verificamos que a maioria dos trabalhos não receberam ou não declararam ter recebido qualquer tipo de financiamento (Figura 2). Encontramos 24 estudos (32\%) que foram financiados por 7 agências, sendo que à maioria das pesquisas foram financiadas por agências do governo federal, CAPES (12) e CNPq (5). As demais, 4 agências são de governos estaduais, a saber: Goiás (1), Paraná (2), Minas Gerais (1) e São Paulo (2). Somente uma é de universidade privada, a Mackpesquisa.

Figura 2 - Distribuição de pesquisas financiadas por agências de fomento

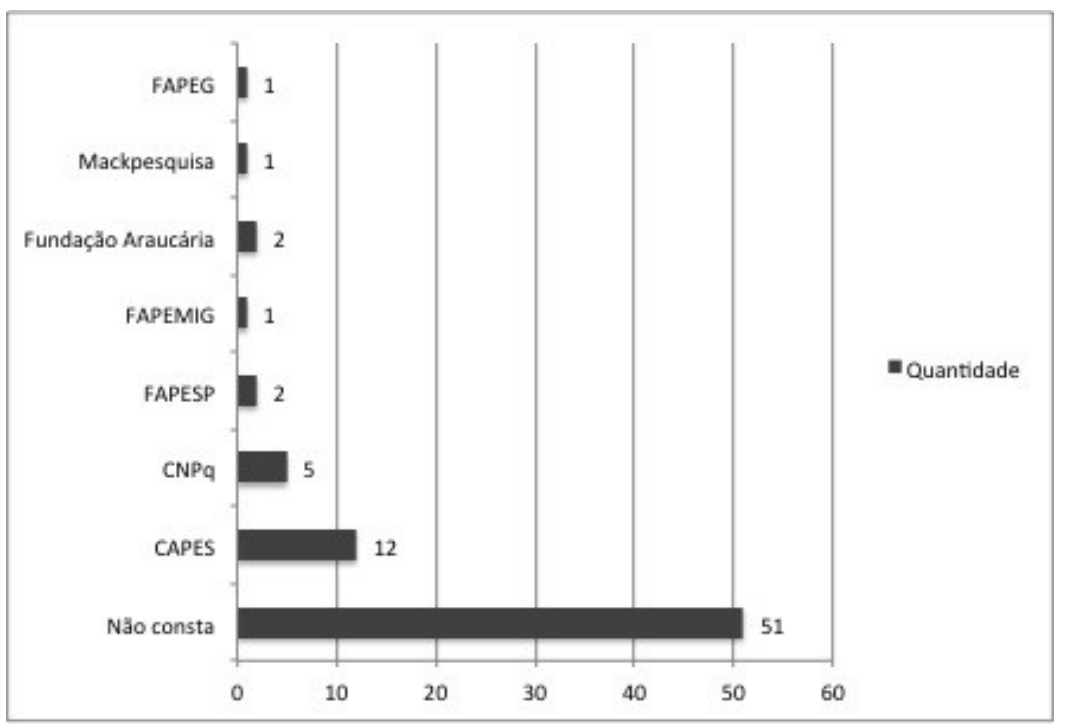

Fonte: BDTD/IBICT, 2014. Elaboração dos autores.

O corpus documental analisado apresentou 225 palavras-chave atribuídas pelos autores dos 75 trabalhos. Ao descrever o conteúdo do documento e refletir as temáticas abordadas pelos autores, as palavras-chave permitem o acesso dos leitores ao texto produzido (BELLO, PIZZANI, HAYASHI, 2010). Assim, foi construída uma "nuvem de palavras" para demonstrar visualmente a frequência de ocorrência de termos dentro de um texto (Figura 3). Esse recurso gráfico está disponível gratuitamente na web e utiliza a contagem das palavras que apareceram mais vezes no conjunto definido, ampliando-as visualmente em escala de tamanho e cores, permitindo uma percepção visual da frequência de ocorrência dos termos. Assim, por meio das palavras-chave, a temática que ficou mais evidente foi "Educação", e, em seguida, "Deficiência", "APAE" e "Síndrome de Down", e também tiveram significativa presença: "paralisia cerebral", "deficiência mental", "família". Percebemos que termos específicos da área da saúde tiveram pouca frequência, embora existam em maior número na forma de termos específicos da referida área. 
Desse modo, as temáticas refletem o fato de a APAE ser um complexo de serviços na área da educação, saúde, assistência social, tendo como público alvo as pessoas com deficiência física e intelectual e síndrome de down. Além do fato da instituição considerar a família e amigos do excepcional como o eixo principal e aglutinador de suas atividades, tendo em vista defenderem a sua autonomia como não transferível ao setor público (JANNUZZI; CAIADO, 2013).

Figura 3 - Temáticas das pesquisas

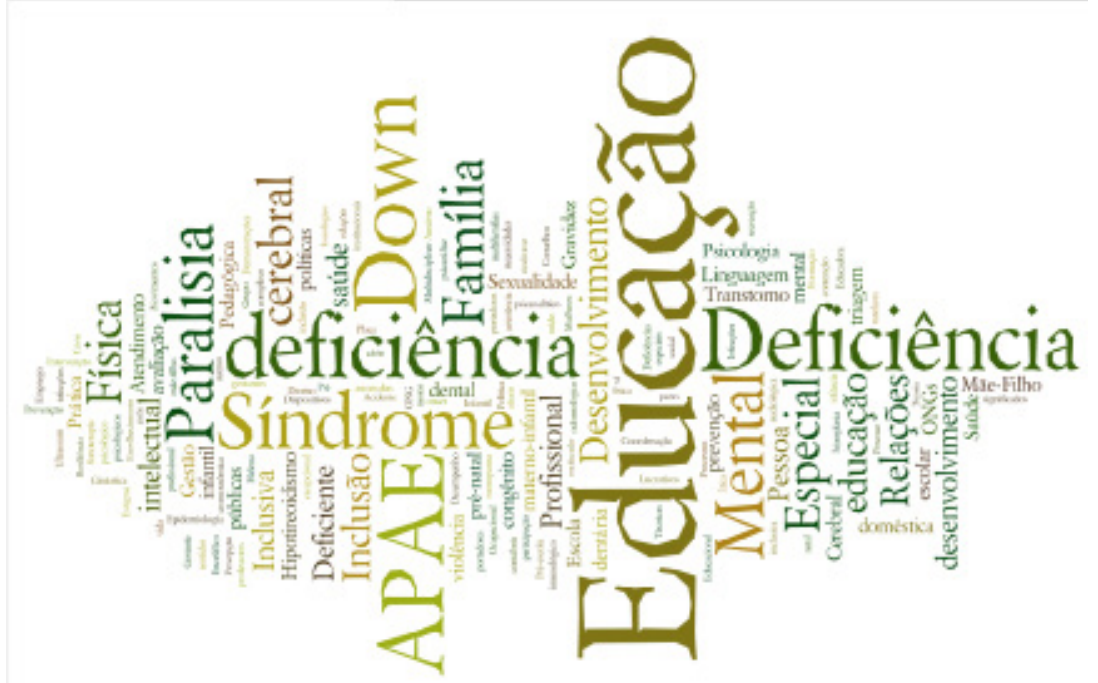

Fonte: Elaboração dos autores.

Aliás, essas temáticas também se vinculam a 7 campos de conhecimento ( Tabela 2). A maioria dos trabalhos sobre APAE foram realizados na área da Saúde e depois na da Educação, a área da Psicologia também teve uma presença relevante e, as demais áreas de conhecimento, tiveram pouca participação. Esses dados revelam que, por muito tempo na APAE, houve um enfoque médico-pedagógico sobre a deficiência, que centra nas limitaçôes biológicas do sujeito, além do fato de que a APAE possui uma proposta educacional para o seu público (JANNUZZI, CAIADO, 2013). 
Tabela 2 - Configuração dos campos de conhecimentos das pesquisas

\begin{tabular}{ccc}
\hline Campos do conhecimento & Quantidade & $\begin{array}{c}\text { Frequência } \\
\text { (aproximado) }\end{array}$ \\
\hline Saúde & 31 & $41 \%$ \\
Educaçáo & 20 & $27 \%$ \\
\hline Psicologia & 13 & $17 \%$ \\
Assistência Social & 5 & $6,5 \%$ \\
Trabalho & 3 & $4 \%$ \\
Administraçáo & 2 & $3 \%$ \\
\hline Ciência Política & 1 & $1,5 \%$ \\
Total & 75 & $100 \%$ \\
\hline
\end{tabular}

Fonte: Elaboração dos autores.

Acrescentamos que 64 trabalhos foram realizados na APAE e 11 sobre a APAE. Isso aponta que essa entidade é mais uma fonte de coleta de dados, do que de estudos que façam uma avaliação institucional e política dos seus trabalhos. Tendo presente essas consideraçôes, realizamos análise de conteúdo dos 11 trabalhos com relação aos seus objetivos, tipos de estudo e síntese dos resultados.

\section{Estudos sobre a APAE: o que dizem as pesquisas?}

No Quadro 1, podemos observar que há nas pesquisas diferentes objetivos que perpassam por três ideias principais: história, práticas pedagógicas e gestão das organizaçóes. A primeira ideia corresponde a um objetivo de analisar a história de APAE-SP (SILVA, 2000). A segunda ideia refere-se às três pesquisas que se propuseram investigar práticas pedagógicas no que diz respeito aos procedimentos didáticos na alfabetização de crianças com deficiência intelectual (LIMA, 2002) e as aulas práticas da Educação Física (PIFFER, 2011; SIMÃO, 2013). E a terceira ideia abrange 7 pesquisas relacionadas a análise da gestão da APAE nos aspectos educacionais, administrativos e políticos (LOSEKANN, 2005; WINCKLER, 2005; SALABERRY, 2007; DIAS, 2010; JOHANN, 2011; CARVALHO, 2012; LOUREIRO, 2013). 
Quadro 1 - Objetivos das pesquisas sobre as APAES

\begin{tabular}{|c|c|}
\hline Autores/Ano & Objetivos \\
\hline Silva (2000) & $\begin{array}{l}\text { Analisar a história da APAE-SP, desde seus primórdios até o momento atual, tendo como objeto } \\
\text { de cstudo a ceducaçáo profissional ministrada pcla referida cntidade no periodo de } 1961 \text { a } 1999 .\end{array}$ \\
\hline Lima (2002) & $\begin{array}{l}\text { Identificar os procedimentos didático-metodológicos utilizados pelos professores da APAE no } \\
\text { processo de alfabetizaçáo dos alunos portadores de necessidades educativas especiais na área } \\
\text { mental em nível moderado. }\end{array}$ \\
\hline Losekann (2005) & $\begin{array}{l}\text { Identificar elementos que compóem e exemplificam a atuaçáo de organizaçóes da sociedade civil } \\
\text { brasileira, principalmente sua relaçáo com o Estado, através da experiência destas entidades } \\
\text { selecionadas (a APAE Porto Alegre, a APAE Novo Hamburgo e a Federaçáo das APAES-RS). }\end{array}$ \\
\hline Winckler (2005) & $\begin{array}{l}\text { Estudar o histórico e as demonstraçóes contábeis da APAE de Blumenau, entidade tradicional } \\
\text { desse scgmento como exemplo tipificador das cntidades sem fins lucrativos, no que concerne, } \\
\text { principalmente, a estarem (ou náo) seguindo o princípio da evidenciaçáo. }\end{array}$ \\
\hline Salaberry (2007) & $\begin{array}{l}\text { Verificar a prática da proposta APAE EDUCADORA no desenvolvimento das açōes cducativas } \\
\text { da unidade escolar da APAE de Porto Alegre. }\end{array}$ \\
\hline Dias (2010) & $\begin{array}{l}\text { Construir referenciais para a consolidaçáo do atendimento educacional especializado } \\
\text { complementar da APAE de Săo Paulo, como scrviço de apoio ans sistemas de cnsino na inclusăo } \\
\text { escolar do aluno com deficiência intelectual. }\end{array}$ \\
\hline Johann (2011) & $\begin{array}{l}\text { Analisar os Programas de Educaçáo Profissional que fazem parte do Processo de Educaçăo } \\
\text { Profissional e Colocaçáo no Trabalho (PECT) da APAE de Toledo-PR, na década de } 1990 .\end{array}$ \\
\hline Piffer (2011) & $\begin{array}{l}\text { Compreender, por meio das observaçóes das aulas, dos dizeres da professora e dos seus educandos, } \\
\text { a prática pedagógica da disciplina de Educaçăo Física numa Instituiçăo de Educaçăo Especial / } \\
\text { APAE de Santa Catarina. }\end{array}$ \\
\hline Carvalho (2012) & $\begin{array}{l}\text { Apresentar o desempenho do trabalho realizado pela APAE e do Instituto Irmáos Maristas na } \\
\text { cidade de Iguatu-CE, sob o olhar da Ética do Cuidado. }\end{array}$ \\
\hline Loureiro (2013) & $\begin{array}{l}\text { Compreender a organizaçio e o funcionamento da Educaçáo Especial no município de Porto } \\
\text { Ferrcira-SP. }\end{array}$ \\
\hline Simáo (2013) & $\begin{array}{l}\text { Analisar a inclusáo do deficiente intelectual a partir das príticas dos professores de Educaçáo } \\
\text { Física da APAF; conhocer o perfil do professor de Educaçáo Física que atua nas cscolas da APAF; } \\
\text { caracterizar o currículo escolar de Educaçáo Fisica e analisar as práticas pedagógicas dos } \\
\text { professores dessa disciplina desenvolvidas nessas escolas. }\end{array}$ \\
\hline
\end{tabular}

Fonte: BDTD/IBICT, 2014. Elaboração dos autores.

Entendemos que, apesar dos pesquisadores terem diferentes objetos na análise da gestáo, eles procuraram compreender o complexo de serviços na APAE, uma vez que há projetos/programas elaborados pela Federação Nacional das APAES (FENAPAES) que organizam as atividades das unidades apaeanas, tais como: Projeto Águia, Projeto Sinergia e APAE Educadora. Este último foi objeto de estudo de Salaberry (2007), que se refere a uma proposta orientadora das açóes educacionais para as pessoas com deficiência intelectual atendidas nas APAES. O projeto também contempla a elaboração de instrumentos/estratégias para concretizar as metas estabelecidas no Projeto Águia.

Ressaltamos que analisar o processo educacional nas APAES fez parte da maioria das pesquisas, uma vez que a instituição presta o serviço de educação de forma substitutiva à Educação Básica. Acrescentamos, também, que os estudos na análise da gestâo das APAES podem estar relacionados ao fato de que, entre 2005 e 2013, o movimento apaeano se concentrou na sua organização gerencial, estruturando-se burocraticamente e ampliando meios para garantir sua manutenção, em virtude da política da "educação inclusiva" (JANNUZZI; CAIADO, 2013). 
Essas temáticas implicaram na escolha de diferentes tipos de estudo (Quadro 2), os quais identificamos que a maioria de trabalhos ( $n=6)$ consistem em estudos de caso. Depois, 2 estudos foram realizados como Estudo de Caso múltiplo e dois como Histórico e documental. Somente houve um estudo do tipo pesquisa-ação.

Quadro 2 - Classificação por tipos de estudo

\begin{tabular}{|l|l|}
\hline \multicolumn{1}{|c|}{ Autores/Ano } & \multicolumn{1}{c|}{ Tipo de Estudo } \\
\hline Silva (2000); Johann (2011). & Histórico e documental \\
\hline $\begin{array}{l}\text { Lima (2002); Winckler (2005); Salaberry (2007); Piffer (2011); } \\
\text { Loureiro (2013); Simáo (2013). }\end{array}$ & Estudo de caso \\
\hline Losekann (2005); Carvalho (2012). & Estudo de caso múltiplo \\
\hline Dias (2010) & Pesquisa-açáo \\
\hline
\end{tabular}

Fonte: Elaboração dos autores.

Dessa maneira, os tipos de estudos propiciaram obter diferentes resultados em três distintas áreas (Quadro 3). $\mathrm{Na}$ área da Educação, discutiu-se os resultados relacionados às temáticas da educação profissional (SILVA, 2000; JOHANN, 2011), da alfabetização (LIMA, 2002), das práticas pedagógicas (SALABERRY, 2007; DIAS, 2010; PIFFER, 2011; SIMÃO, 2013) e da história e organização da instituição (LOUREIRO, 2013). Na área da Ciência Política, Losekann (2005) aborda a articulação da APAE com o movimento apaeano, e a relação entre Estado e sociedade. E na área da Administraçáo, Carvalho (2012) constata que as unidades apaeanas se aproximam do referencial da Ética do cuidado, e Winckler (2005) realiza uma avaliação contábil de uma determinada APAE.

Quadro 3 - Resultados obtidos nas pesquisas analisadas

\begin{tabular}{|c|c|}
\hline Autores/Ano & Resultados \\
\hline Silva (2000) & $\begin{array}{l}\mathrm{O} \text { trabalho coletivo afigura-se como proposta alternativa à realidade hodiernamente vivenciada } \\
\text { pelo deficiente mental na sociedade capitalista a execuçáo do trabalho nos moldes cooperativistas, } \\
\text { tendo na APAE-SP a entidade apta a assumir tal proposta. }\end{array}$ \\
\hline Lima (2002) & $\begin{array}{l}\text { Conclui-se que os procedimentos didático-metodológicos utilizados pelos professores da APAE no } \\
\text { processo de alfabetizaçáo dos alunos PNEE em nível mental moderado embasa-se numa tendência } \\
\text { tradicional de ensino. Assim, os objetivos, as estratégias de ensino e o tipo de avaliaçáo náo se } \\
\text { constituem numa proposta inovadora capaz de propiciar aos alunos o desenvolvimento } \\
\text { significativo da leitura e da escrita. Os resultados encontrados apontam, portanto, para a } \\
\text { necessidade de os professores direcionarem um encaminhamento metodológico diferenciado, em } \\
\text { que a criança portadora de deficiência mental passe a ser o sujeito na busca do seu conhecimento, } \\
\text { possibilitando à criança ir além dos conhecimentos concretos, o que implica estimulá-la a codificar } \\
\text { as suas experiências, ou seja, representar operando com símbolos. }\end{array}$ \\
\hline Losekann (2005) & $\begin{array}{l}\text { Identificaçáo dos espaços de atuaçáo politica das APAES e os mecanismos utilizados na formaçáo } \\
\text { deste espaço, desde a incorporaçáo de práticas comuns à outras organizaçees da sociedade civil, } \\
\text { como a participaçáo em conselhos e a representaçáo de um público perante o Estado, até os } \\
\text { aspectos que revelam uma estrutura de atuaçáo tradicionalmente vinculada à filantropia. }\end{array}$ \\
\hline Winckler (2005) & $\begin{array}{l}\text { As conclusốes sáo de que, de maneira geral, as demonstraçóes contábeis da APAE de Blumenau } \\
\text { atendem ao princípio da evidenciaçáo, no sentido de conseguirem espelhar a situaçáo real da } \\
\text { entidade aos usuários às informaçóes contábeis. }\end{array}$ \\
\hline Salaberry (2007) & $\begin{array}{l}\text { Constatou que náo há uma concepçáo única em relaçáo a Pessoa com Deficiência Mental na } \\
\text { comunidade escolar. Quanto a concepçáo da instituiçáo APAE, predominou entre os participantes } \\
\text { a Concepçáo Inclusiva/Transformadora. Quanto as praticas na escola, a funçáo da Unidade Escola } \\
\text { e sua gestáo encontram-se numa concepçáo Inclusiva/Transformadora. Com relaçáo ao ensino, } \\
\text { aprendizagem e avaliaçáo, se aproxima a concepçáo Inclusiva/Transformadora, mas, em relaçáo a } \\
\text { proposta da APAE EDUCADORA, encontra-se fragilizada em suas açóes. }\end{array}$ \\
\hline
\end{tabular}


Continuação do Quadro 3

\begin{tabular}{|c|c|}
\hline Dias (2010) & $\begin{array}{l}\text { A construçáo dos referenciais gerou reflexóes em duas perspectivas. A primeira diz respeito à } \\
\text { conceppéo de que esse atendimento deve incidir sobre o funcionamento cognitivo, o qual se } \\
\text { constitui como a principal barreira no processo de aprendizagem de pessoas com deficiência } \\
\text { intelectual. E a complementaridade entre o professor especializado e o professor da classe comum } \\
\text { exige mudanças na cultura dos profissionais de educaçáo, pois ainda é frequente a concepçáo de } \\
\text { que o professor cspecializado ć o responsável pclos processos de cnsino c de aprendizagem dos } \\
\text { alunos com deficiência intelectual, mesmo quando eles estáo inseridos na classe comum. A segunda } \\
\text { perspectiva se relaciona às beses conceituais do atendimento, ou seja, ao aprofundamento teórico } \\
\text { sobre a cogniçáo c a sua indissociável relaçăo com a afctividade c a linguagem no desenvolvimento } \\
\text { humano. }\end{array}$ \\
\hline Johann (2011) & $\begin{array}{l}\text { Constatou-se que, desde 1998, } 2.198 \text { alunos com deficiència passaram pelos programas do PECT, } \\
\text { sendo que, até o final de 2010, } 34 \text { alunos foram inseridos no mercado de trabalho. }\end{array}$ \\
\hline Piffer (2011) & 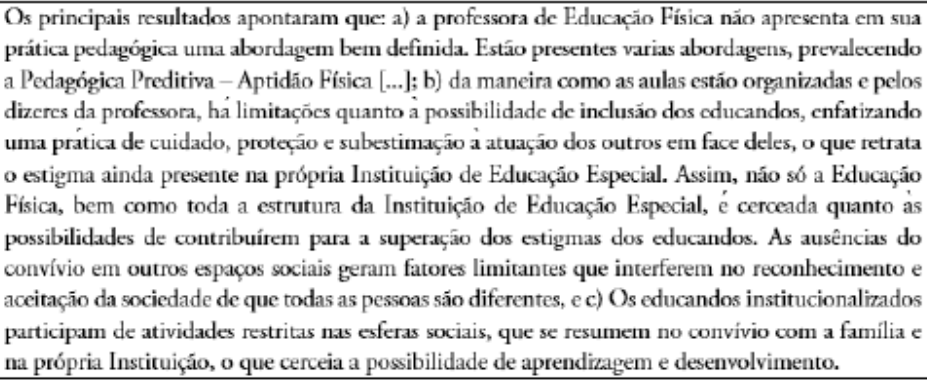 \\
\hline Carvalho (2012) & $\begin{array}{l}\text { Por fim, promove-se uma avaliaçăo das atividades e projetos desenvolvidos por essas organizaçócs, } \\
\text { buseada nas estruturas físicas e humanas e alicerçadas na Êtica do Cuidado. }\end{array}$ \\
\hline Loureiro (2013) & $\begin{array}{l}\text { Os resultados obtidos apontam no sentido de constatarmos: a) a importáncia que a instituiçáo } \\
\text { privada, de cunho filantrópico (APAE), tem desde sua criaçắo, atc os dias de hoje; b) a ausência de } \\
\text { um projeto político destinado aos alunos com deficiências nas escolas búsicas do município; c) a } \\
\text { "ausência" de um movimento social das pessoas com deficièncias no município pesquisado. }\end{array}$ \\
\hline Simâo (2013) & $\begin{array}{l}\text { Considera-se que as Políticas Públicas para a inclusio devem ser concretizadas na forma de } \\
\text { programas de capaciaçáo e acompanhamento contínuo. Deve-se orientar o trabalho docente na } \\
\text { perspectiva de diminuir gradativamente a exclusáo escolar. E as atividades de Educaçáo Física } \\
\text { devem ser sustentadas em uma formaçáo de qualidade para os professores. }\end{array}$ \\
\hline
\end{tabular}

Fonte: BDTD/IBICT, 2014. Elaboração dos autores.

No geral, percebemos diversos resultados da produção científica sobre as APAES, mas que se aproximam daqueles localizados por Meletti (2006) que identificou, nas APAES, a manutenção da pessoa com deficiência intelectual no âmbito da filantropia, a indistinção entre reabilitação e educação e o não acesso aos processos efetivos de escolarização, e a manutenção da condição segregada da pessoa com deficiência intelectual na instituição especial "inclusiva".

Os resultados das pesquisas apontam que, nas APAES, existem: a) ênfase das atividades educacionais para a profissionalização da pessoa com deficiência, bem como a preocupação com os exercícios da Educaçáo Física; b) discussão de que a alfabetização das crianças requer um novo método, assim com o ensino, aprendizagem e avaliação; c) necessidade dos serviços das unidades apaeanas estimular a linguagem e a interação para promover o desenvolvimento cognitivo; d) preocupação das entidades na sua organização administrativa e financeira. 
Esses resultados estão influenciados pela forma organizacional das APAES, bem como pelos projetos e programas das FENAPAES que incentivam a educação profissional e o trabalho com o corpo humano. Mas as pesquisas revelam que as instituiçôes apaeanas deixaram a desejar na contribuição da aquisição do conhecimento, os quais se devem ao desenvolvimento de habilidades linguísticas, lógicas e sociais.

\section{Considerações finais}

A produção científica sobre a APAE evidencia a atuação filantrópica da instituição que é reconhecida como um dos maiores movimentos do Brasil e do mundo para as pessoas com deficiência. Muitos pesquisadores se propuseram a compreender as entidades ou analisar as condiçóes de vida das pessoas com deficiência e da familia, mas há poucos estudos que se dedicaram a fazer uma avaliação crítica dos serviços das APAES.

No presente estudo, identificamos algumas fragilidades nas pesquisas. Muitos trabalhos não declararam se houve apoio financeiro ou nấo na realização da pesquisa, bem como náo esclareceram quais foram as abordagens metodológicas utilizadas, e técnicas para a coleta e análise dos dados. No que diz respeito à fundamentaçáo teórica, pouquíssimos trabalhos mencionaram, o que dificultou uma melhor compreensão sobre a concepçáa de deficiência e educação.

Por isso, são necessários novos estudos que se proponham fazer uma leitura integral das teses e dissertaçóes, para compreender sob quais bases epistemológicas se sustentam. Além de ampliar os indicadores bibliométricos ou também se dedicar a uma análise cientométrica em revistas sobre a temática APAE, tendo por objetivo investigar o impacto do assunto na seara acadêmica.

Portanto, as pesquisas analisadas reforçam que a APAE é uma instituição de peso na oferta de serviços na área da Educaçáo e Saúde para as pessoas com deficiência. O serviço na área da Educaçáo instiga-nos a pensar que urge aos pesquisadores problematizar a atuaçáo dessa entidade, pois a educaçáo escolar deve ser política pública social.

\section{Referências}

BELLO, S. F. Interfaces Educação Especial e Fonoaudiologia: um estudo bibliométrico baseado na produção científica de dissertaçóes e teses. 2009. 185f. Dissertação (Mestrado em Educação Especial), Programa de PósGraduação em Educação Especial, Universidade Federal de São Carlos, São Carlos, 2009.

BELLO, S. F. Análise de redes de colaboração científica entre a Educaçáo Especial e a Fonoaudiologia. Sáo Carlos, 2013. 228f. Tese (Doutorado em Educação Especial), Programa de Pós-Graduação em Educação Especial, Universidade Federal de São Carlos, São Carlos, 2013.

BELLO, S.F., PIZZANI, L., HAYASHI, M.C.P.I. Descritores e suas interrelaçōes: fonoaudiologia e educação especial. Distúrbios da Comunicaçáo, v. 22, n. 2, p.149-57, 2010.

BRASIL. Política Nacional de Educação Especial na perspectiva da educação inclusiva. Brasília, DF: MEC/ SEESP, 2008.

BRASIL. Lei n. 13.005, de 25 de junho de 2014. Dispóe sobre o Plano Nacional de Educação. Brasília, DF: Presidência da República, 2014.

BRAVO, A. D. Análise bibliométrica da produçáo científica sobre direitos das pessoas com deficiência. São Carlos, 2013. 135f. Tese (Doutorado em Educação Especial), Programa de Pós-Graduação em Educação Especial, Universidade Federal de São Carlos, São Carlos, 2013. 
CARVALHO, E. A. de. O trabalho realizado por ONGs em Iguatu-CE na perspectiva da Ética do Cuidado. São Leopoldo, 2012. 73f. Dissertação (Mestrado Profissionalizante em Teologia), Programa de Pós-Graduação em Teologia, Escola Superior de Teologia, São Leopoldo, 2012.

COPPEDE, A. C. Motricidade fina na criança: um estudo bibliométrico da literatura nacional e internacional. 2012. 149f. Dissertaçáo (Mestrado em Educação Especial), Programa de Pós-Graduaçáo em Educaçáo Especial, Universidade Federal de São Carlos, São Carlos, 2012.

DIAS, M. C. Atendimento Educacional Especializado complementar e a deficiência intelectual: consideraçôes sobre a efetivação do direito à educação. 2010. 156f. Dissertação (Mestrado em Educação), Programa de Pós-Graduação em Educação, Universidade São Paulo, São Paulo, 2010.

FEDERAÇÃO NACIONAL DAS APAES. (FENAPAES). Rede APAE e sua história. Disponível em: <http:// www.apaebrasil.org.br/artigo.phtml?a=2>. Acesso em: 28 maio 2014.

GARRUTTI, E. A. Procedimentos de pesquisa na produçáo científica discente do PPGEEs/UFSCar. 2007. 188f. Dissertação (Mestrado em Educação Especial), Programa de Pós-Graduação em Educação Especial, Universidade Federal de São Carlos, São Carlos, 2007.

HAYASHI, M. C. P. I. H. Análise bibliométrica: leituras teóricas, procedimentos metodológicos e protocolo de coleta de dados. São Carlos, 2014. (mimeo).

HAYASHI, M. C. P. I. H.; HAYASHI, C. R. M.; MARTINEZ, C. M. S. Estudos sobre jovens e juventude: diferentes percursos refletidos na produção científica brasileira. Educaçáo, Sociedade \& Culturas, Lisboa, Universidade do Porto, n. 27, p. 131.154, 2008.

JANNUZZI, G. de M.; CAIADO, K. R. M. APAE: 1954 a 2011 - algumas reflexóes. Campinas, SP: Autores Associados, 2013.

JOHANN, J. Programas de educaçáo profissional na APAE de Toledo - Paraná. 104f. Dissertação (Mestrado em Educação), Programa de Pós-Graduação em Educação, Universidade Estadual do Oeste do Paraná, Cascavel, 2011.

LIMA, T. de F. A. de. Procedimentos didático-metodológicos utilizados pelos professores da APAE no processo de alfabetizaçáo dos alunos portadores de deficiência mental moderada. 2002. 138f. Dissertaçáo (Mestrado em Educação Brasileira), Programa de Pós-Graduação em Educação, Universidade Federal de Uberlândia, Uberlândia, 2002.

LOSEKANN, C. Espaços de participaçáo política: um estudo da APAE. 2005. 109f. Dissertação (Mestrado em Ciência Política), Programa de Pós-Graduação em Ciência Política, Universidade Federal do Rio Grande do Sul, Porto Alegre, 2005.

LOUREIRO, A. D. T. A educaçáo especial no município de Porto Ferreira-SP: 1972 a 2011. 2013. $140 f$. Dissertação (Mestrado em Educação Especial), Programa de Pós-Graduaçâoo em Educação Especial, Universidade Federal de São Carlos, São Carlos, 2013.

MELETTI, S. M. F. Educaçáo escolar da pessoa com deficiência mental em instituiçóes de educaçáo especial: da política à instituiçáo concreta. 2006. 125f. Tese (Doutorado em Psicologia), Programa de Pós-Graduação em Psicologia, Universidade São Paulo, São Paulo, 2006.

MINAYO, M. C. de S. O desafio do conhecimento: pesquisa qualitativa em saúde. 9. ed. revista e aprimorada. São Paulo: Ed. Hucitec, 2006.

NUNES, A. C. Produçáo científica em Retinopatia da Prematuridade: um estudo bibliométrico do fator de risco para alteraçôes. 2012. 110f. Dissertação (Mestrado em Educação Especial), Programa de Pós-Graduação em Educação Especial, São Carlos, Universidade Federal de São Carlos, 2012.

PEREIRA, M. A.; JUNIOR, A. F.; HAYASHI, M. C. P. I. Os Institutos Históricos e Geográficos no Brasil: estudo bibliométrico no banco de teses da CAPES. In: HAYASHI, M. C. P. I.; FARIA, L. I. L.; HAYASHI, C.R. M. (Org.). Bibliometria e cientometria: estudos temáticos. São Carlos: Pedro e João Editores, 2013. p. 229-246.

PIFFER, G. D. "Digamos que seja mais prazeroso lecionar aqui do que na escola regular”: A Educação Física numa escola especial. 2011. 199f. Dissertação (Mestrado em Educação), Programa de Pós-Graduação em Educação, Universidade Regional de Blumenau, Blumenau, 2011.

PIZZANI, L. O estado da arte da produçáo científica em educaçáo especial na Biblioteca Virtual em Saúde (BVS): um estudo bibliométrico. 2008. 160f. Dissertação (Mestrado em Educação Especial), Programa de PósGraduação em Educação Especial, Universidade Federal de São Carlos, São Carlos, 2008. 
PIZZANI, L. O campo de estudo sobre prematuridade no Banco de Teses da Capes: produçâo científica e redes de colaboração em Educaçáo Especial. 2012. 277f. Tese (Doutorado em Educação Especial), Programa de Pós-Graduação em Educação Especial, Universidade Federal de São Carlos, São Carlos, 2012.

PROCURADORIA JURÍDICA (FENAPAES). A Rede APAE no Brasil. Disponível em: <http://www.apaebrasil.org.br>. Acesso em: 11 jul. 2014.

RIGOLIN, C. C. D.; HAYASHI, C. R. M.; HAYASHI, M. C. P. I. Métricas da participação feminina na ciência e na tecnologia no contexto dos INCTs: primeiras aproximaçóes. Liinc em Revista, Rio de Janeiro, v. 9, p. 143-170, 2013.

SACARDO, M. S. Publicação científica derivada das dissertaçóes e teses na interface entre educaçáo física e educaçáo especial. 2006. 134f. Dissertação (Mestrado em Educação Especial), Programa de Pós-Graduação em Educaçấo Especial, Universidade Federal de São Carlos, São Carlos, 2006.

SACARDO, M. S. Estudo bibliométrico e epistemológico da produção científica em Educação Física na Região Centro-Oeste do Brasil. 2012. 255f. Tese (Doutorado em Educação Especial), Programa de Pós-Graduação em Educação Especial, Universidade Federal de São Carlos, São Carlos, 2012.

SALABERRY, N. T. M. A APAE educadora: na prática de uma unidade da APAE de 2007. 131f. Dissertação (Mestrado em Educação), Programa de Pós-Graduação em Educação, Pontifícia Universidade Católica de Porto Alegre, Porto Alegre, 2007.

SILVA, A. G. da. A Educaçáo Profissional de pessoas com deficiência mental: a história da relaçáo Educação Especial/Trabalho na APAE-SP. 2000. 271f. Tese (Doutorado em Educação), Programa de Pós-Graduação em Educação, Universidade Estadual de Campinas, Campinas, 2000.

SILVA, M. R. da. Análise bibliométrica da produção científica docente do Programa de Pós-Graduaçáo em Educaçáo Especial da UFSCar: 1998-2003. 2004. 168f. Dissertação (Mestrado em Educaçáo Especial), Programa de Pós-Graduaçáo em Educação Especial, Universidade Federal de São Carlos, São Carlos, 2004.

SILVA, R. C. da. Indicadores bibliométricos da produçáo científica em educaçáo especial: estudo da revista educação especial (2000-2006). 2008. 126f. Dissertação (Mestrado em Educaçấo Especial), Programa de PósGraduação em Educação Especial, Universidade Federal de São Carlos, São Carlos, 2008.

SILVA, M. R. da; HAYASHI, C. R. M.; HAYASHI, M. C. P. I. Análise bibliométrica e cientométrica: desafios para especialistas que atuam no campo. InCID: Revista de Ciência da Informação e Documentação, Ribeirão Preto, USP, v. 2, p. 110-129, 2011.

SILVA, R. C. da. Produçáo cientifica em Sociologia da Educação: um estudo bibliométrico do banco de teses da CAPES. 2013. 173f. Tese (Doutorado em Educação), Programa de Pós-Graduação em Educação, Universidade Federal de São Carlos, São Carlos, 2013.

SIMÃO, L. J. Inclusão escolar: deficiência intelectual e as práticas pedagógicas de educação física das APAES de Curitiba. 2013. 110f. Dissertação (Mestrado em Educação), Programa de Pós-Graduação em Educação, Universidade Tuiuti do Paraná, Curitiba, 2013.

WINCKLER, P. R. Evidenciaçáo contábil de entidades sem finalidade de lucro (ESFL): um estudo de caso sobre a Associação de Pais e Amigos dos Excepcionais de Blumenau. 168f. Dissertação (Mestrado em Ciências Contábeis), Programa de Pós-Graduação em Ciências Contábeis, Universidade Regional de Blumenau, Blumenau, 2005.

\section{Notas}

${ }^{1}$ Decidiu-se pelo IBICT porque o Banco de Teses da CAPES estava passando por reformulação e atualmente, só apresenta registros a partir de 2010, enquanto que a BDTD/IBICT possui registros de anos anteriores. Em uma busca prospectiva, foram encontrados 30 registros no Banco de Teses da CAPES e 83 registros na BDTD. 
João Henrique da Silva - Maria Cristina Piumbato Innocentini Hayashi

\section{Correspondência}

Joáo Henrique da Silva - Universidade Federal de São Carlos, Centro de Educação e Ciências Humanas. Bairro: Jardim Guanabara. CEP: 13565-905. São Carlos, São Paulo, Brasil.

E-mail: jhsilvamg@icloud.com - dmch@ufscar.br

Recebido em 28 de maio de 2015

Aprovado em 25 de maio de 2016 